\title{
HEMODYNAMIC EFFECTS OF QUINIDINE: INCLUDING STUDIES OF CARDIAC WORK AND CORONARY BLOOD FLOW ${ }^{1}$
}

\author{
By GEORGE G. ROWE, DEAN A. EMANUEL, GEORGE M. MAXWELL, JOHN F. \\ BROWN, CESAR CASTILLO, BENJAMIN SCHUSTER,2 Q. R. MURPHY, \\ AND CHARLES W. CRUMPTON
}

\author{
(From the Cardiopulmonary Laboratory and the Departments of Medicine and Physiology, \\ University of Wisconsin Medical School, Madison, Wisc.)
}

(Submitted for publication July 9, 1956; accepted February 28, 1957)

There have been many observations concerning the hemodynamic and electrocardiographic effects of quinidine, both in the experimental animal and in man (1). Although quinidine produces rather profound changes in metabolism at the cellular $(2,3)$ and subcellular (4) level, as well as in the body as a whole, (5), there has been relatively little demonstrable change hemodynamically in normal patients receiving therapeutic doses of the drug (6-8). It appeared that in vivo myocardial metabolic data might be of interest in the study of a dose of quinidine previously shown to be effective in preventing cyclopropane epinephrine arrhythmia in the dog (9). Further justification for studying a dose thus selected is the known poor correlation between blood and tissue quinidine levels (10) which precludes administration of a quantity calculated to reproduce the levels studied in vitro. The data include systemic hemodynamics along with coronary blood flow, myocardial oxygen consumption, and cardiac efficiency.

\section{MATERIAL AND METHODS}

A total of 16 dogs weighing between 16 and 32 kilograms was studied in the post-absorptive state. Cardiac outputs were determined by the Fick principle and coronary blood flows by the nitrous oxide method. The procedure used has been described previously from this laboratory and was similar in this study except that mixed venous blood was withdrawn from the pulmonary artery in all but Dogs Nos. 2 and 3, where the right ventricular blood was utilized as before (11). The plan of anesthesia was $3 \mathrm{mg}$. per kilogram of morphine intramuscularly followed in one hour by $12 \mathrm{mg}$. per kilogram of sodium pentobarbital intravenously. The control observations were begun approximately 1 hour after the pentobarbital was given.

1 This work was supported in part by grants from the National Heart Institute, United States Public Health Service, the Wisconsin Alumni Research Foundation, and the Wisconsin Heart Association.

2 Heart Trainee, United States Public Health Service.
In the first 11 dogs, $15 \mathrm{mg}$. of quinidine gluconate per kilogram were given intravenously over a two-minute period. The second cardiac output was begun approximately 25 minutes after the drug was given and followed immediately by the second determination of coronary blood flow. Because the rapid administration of quinidine produced a very severe hypotension, the last five dogs were given quinidine slowly over twenty minutes and the second observations were begun within two or three minutes after the end of the injection of quinidine. Since the results appeared to be independent of the method of administration, both groups were summarized together.

On two occasions, it was necessary to modify the plan of anesthesia since inadequate anesthesia was obtained and further sedation was required. The first, Dog No. 4, was discarded because large doses of pentobarbital were required prior to the first and second hemodynamic determinations. The other, Dog No. 7, had supplemental morphine and pentobarbital before the first study and remained basal throughout. One further study, Dog No. 6, was discarded from the series because during the placement of cardiac catheters, supraventricular tachycardia occurred with a control rate of 287 beats per minute. Data from Dogs Nos. 4 and 6 are included at the bottom of Table I and excluded from the calculations. In Dog No. 16, data concerning cardiac output and coronary flow were not obtained. All dogs accepted in the series had sinus rhythm except Dog No. 3, which had auricular fibrillation during the first study with a slow rate which converted to sinus rhythm after administration of quinidine.

\section{RESULTS}

Immediately upon administration of the quinidine, whether given rapidly or slowly, there was an acceleration of cardiac rate. This acceleration persisted for as long as the animals were observed and, at the time of the second set of determinations, was increased by 98 per cent $(p<0.001)$. Femoral arterial blood pressure fell with administration of quinidine, particularly when it was given rapidly. The greatest hypotension was reached shortly after the termination of the injection of 
Study of quinidine with dogs

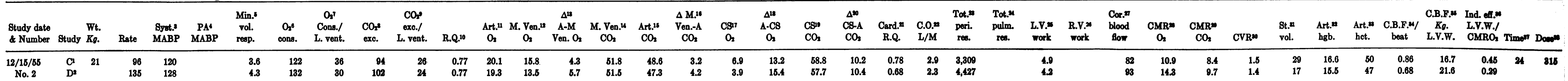

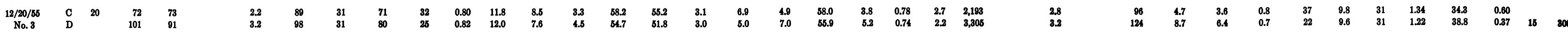

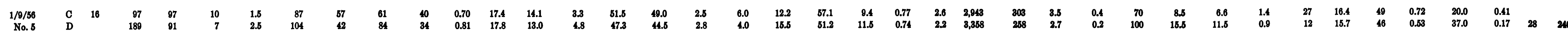

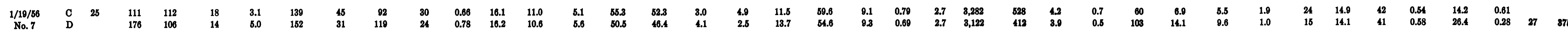

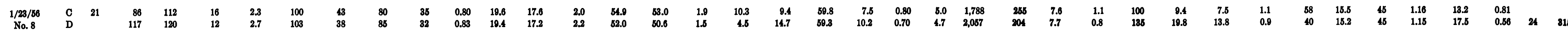

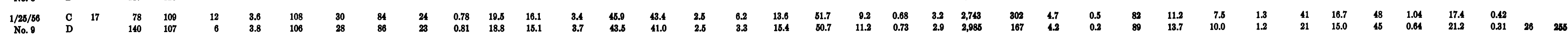

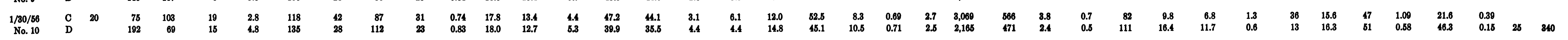

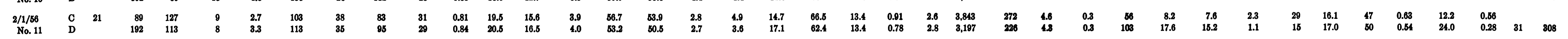

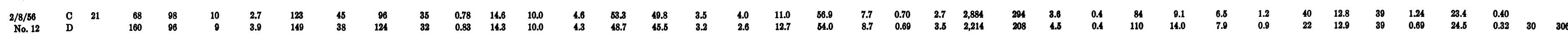

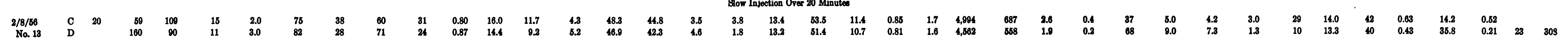

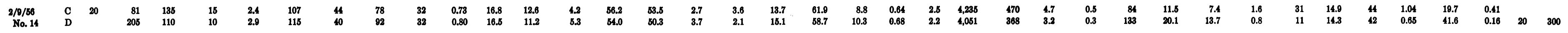

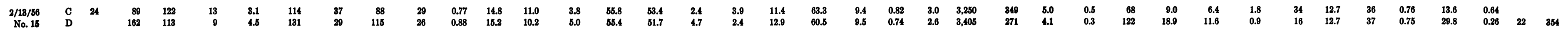

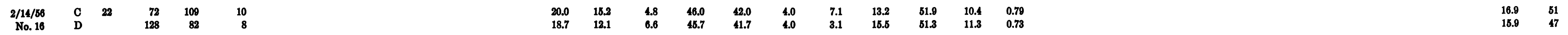

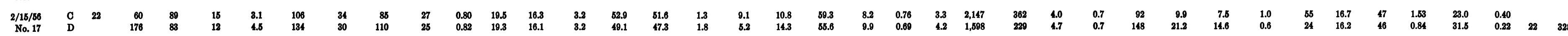

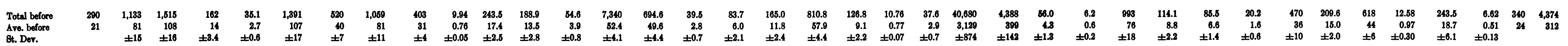

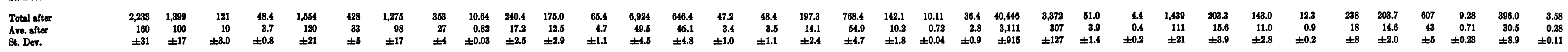

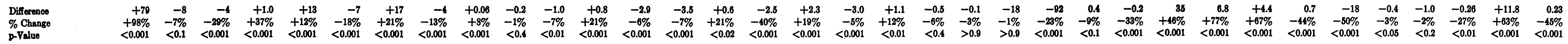

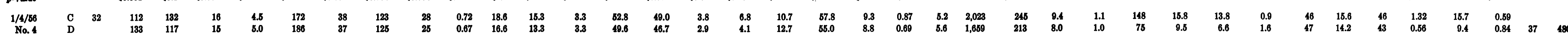

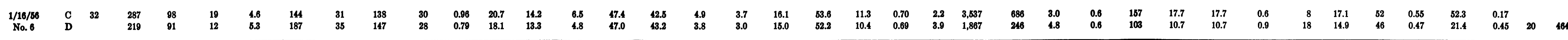

\begin{tabular}{|c|c|c|c|}
\hline 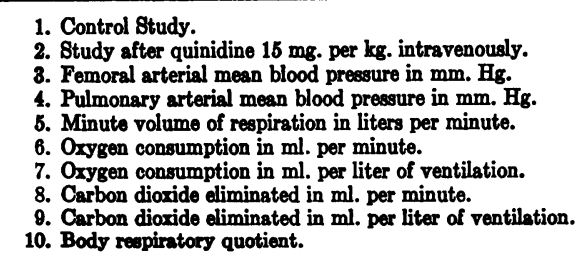 & 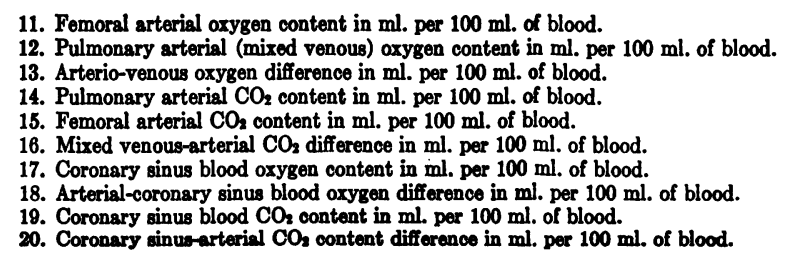 & 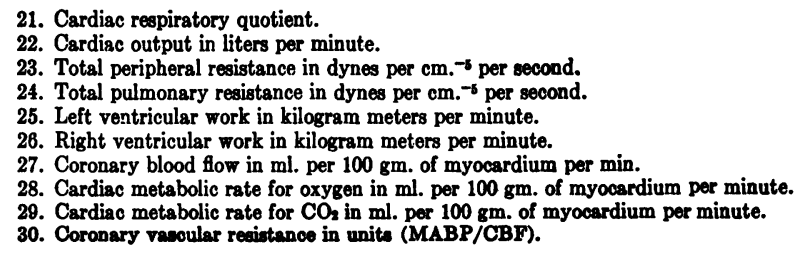 & 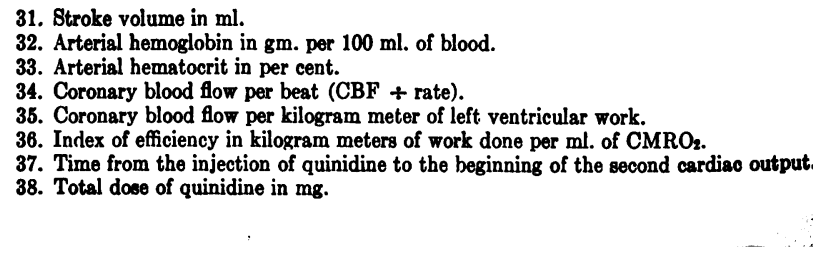 \\
\hline
\end{tabular}


quinidine and pressure then rose again until at the time of the second determinations it averaged 7 per cent lower than the initial observations, which did not represent a significant change $(p<$ 0.1 ). Immediate changes in the pulmonary arterial blood pressure were not as marked as those in the systemic vessels. However, at the time of the second determinations there was a consistent lowering of pulmonary arterial pressure $(-29$ per cent, $p<0.001)$. The minute volume of respiration increased immediately after administration of quinidine and remained elevated at the time of the second cardiac output $(+37$ per cent, $p<0.001$ ). Oxygen consumption and $\mathrm{CO}_{2}$ liberation increased in every case, the former by 12 per cent $(p<$ $0.001)$ and the latter by 21 per cent $(p<0.001)$. Hence there was a significant decrease in exchange of respiratory gases per liter of ventilation $(p<$ 0.001 ).

Although the arterial oxygen content was not changed significantly, the mixed venous $\mathrm{O}_{2}$ content fell $(-7$ per cent, $p<0.01)$ resulting in a significant increase in the arterio-venous blood oxygen difference $(+21$ per cent, $\mathrm{p}<0.001)$. A significant decrease in coronary sinus blood oxygen ( -40 per cent, $\mathrm{p}<0.001)$ was noted as well as an increase in arterial-coronary sinus venous oxygen difference $(+19$ per cent, $\mathrm{p}<0.001)$.

There was no significant change in cardiac output $(-3$ per cent, $\mathrm{p}<0.9)$. Stroke volume, however, fell rather markedly due to the tachycardia ( -50 per cent, $\mathrm{p}<0.001$ ). Total peripheral resistance was unchanged but there was a decrease in total pulmonary vascular resistance in every experiment which was significant $(-23$ per cent, $p<0.001)$. As a manifestation of the unchanged cardiac output and peripheral resistance, left ventricular work was not significantly altered ( -9 per cent, $p<0.1)$. Right ventricular work, on the other hand, was significantly decreased ( -33 per cent, $\mathrm{p}<0.001$ ).

Coronary blood flow was significantly increased $(+46$ per cent, $\mathrm{p}<0.001)$ and since this was accompanied by an increase in arterial-coronary sinus blood oxygen difference $(+19$ per cent, $p<$ 0.001 ), the cardiac metabolic rate for oxygen was markedly increased $(+77$ per cent, $p<0.001)$. If the left ventricular work be divided by oxygen consumption per $100 \mathrm{Gm}$. of myocardium per minute, a figure is obtained which has been called in this study the index of efficiency. This figure is clearly related to the efficiency of the heart, yet avoids estimation of cardiac weight. This index reveals a 45 per cent decrease in myocardial efficiency $(p<0.001)$ after quinidine administration. If calculations be done, assuming the left ventricular weight to be 0.0037 times the body weight, the average cardiac efficiency was 31 per cent before and 16 per cent after quinidine administration.

Examination of the electrocardiogram on these animals was somewhat unsatisfactory. It was especially difficult to determine changes in $T$ waves and $Q T$ interval, because the acceleration was so great during the second set of determinations that the $P$ waves and $T$ waves ran together, making it impossible to measure intervals accurately.

Observations concerning the correlation between each of the factors measured in this study were calculated in the numerical analysis laboratory of the University of Wisconsin and surveyed for significant correlations. Correlation coefficients were determined for every function measured with every other function, in the control data and in the data obtained after quinidine. This was done to attempt to determine what correlations existed in the control animals and how they were modified, if at all, by the drug. These correlations have been summarized in Table II. Only those correlations which were thought to be of interest are included. As indicated in the table, some of those factors which have the highest " $r$ " values owe this, at least partially, to a common factor used in their calculation. It should be emphasized that for this and other reasons, mathematical correlation does not necessarily signify physiological correlation.

\section{DISCUSSION}

Quinidine intravenously in the dosage of $15 \mathrm{mg}$. per kg. was followed by tachycardia associated with a marked increase in myocardial oxygen consumption without any significant change in left ventricular work. Of particular interest was the fact that the increase in myocardial oxygen consumption was associated with an increase in coronary blood flow and an increase in arterial-coronary sinus blood oxygen difference. This is in contrast to previous studies in which an increase in coronary flow was accompanied by either no significant change in arterial-coronary sinus oxygen difference (12) or a decrease (13). 
TABLE II

Correlations between various factors *

\begin{tabular}{|c|c|c|}
\hline & Control & Drug \\
\hline 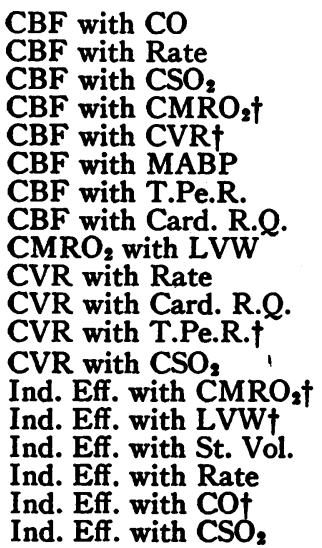 & $\begin{array}{l}+0.67178^{\circ} \\
-0.1272^{\circ} \\
+0.6532^{\Delta} \\
+0.4345 \\
-0.9463 \ddagger \\
-0.3567^{\circ} \\
-0.8129 \ddagger \\
-0.5344^{\circ} \\
+0.5344^{\circ} \\
+0.0585 \\
+0.5411^{\circ} \\
+0.8776 \ddagger \\
-0.5998^{\Delta} \\
-0.3854 \\
+0.5563^{\circ} \\
+0.2288 \\
+0.3064 \\
+0.5447^{\circ} \\
+0.2799\end{array}$ & $\begin{array}{c}+0.6198^{\Delta} \\
0.0000 \\
+0.4652 \\
+0.68578 \\
-0.7825 \ddagger \\
-0.0409 \\
-0.5925^{\Delta} \\
-0.5538^{\circ} \\
+0.5003 \\
-0.1995 \\
+0.3239 \\
+0.66398 \\
-0.4574 \\
-0.0292 \\
+0.8271 \ddagger \\
+0.8872 \ddagger \\
-0.7822 \ddagger \\
+0.6085^{\circ} \\
+0.5902^{\circ}\end{array}$ \\
\hline
\end{tabular}

* Symbols are the same as in Table I.

Levels of significance are indicated as follows:

$$
\begin{aligned}
& \mathrm{p}<0.001 \ddagger \\
& \mathrm{p}<0.01 \\
& \mathrm{p}<0.02 \\
& \mathrm{p}<0.05
\end{aligned}
$$

t Mathematical dependence of the two parameters accounts at least partly for the correlation since a common factor is used in their calculation.

The question of the role of the tachycardia per $s e$ in producing the increase in myocardial oxygen consumption arises. Laurent, Bolene-Williams, Williams, and Katz (14) observed an increase in myocardial oxygen consumption with an increase in heart rate at a relatively constant work load. The authors state that the increment of oxygen consumption by the myocardium was determined primarily by an increase in coronary flow rather than by any increase in myocardial arteriovenous oxygen difference. Preliminary studies in this laboratory utilizing the lightly anesthetized intact animal are in agreement with the observations of Laurent, Bolene-Williams, Williams, and Katz. Hence the tachycardia might contribute to the increase in coronary flow but apparently does not account for the increase in arterial-coronary sinus oxygen difference.

The dose of $15 \mathrm{mg}$. per kilogram of quinidine, demonstrated by Allen, Stutzman, Slocum, and Orth (9) to be effective in preventing cyclopropane epinephrine tachycardia in dogs, is roughly equivalent to a one-gram dose in a $70 \mathrm{~kg}$. man, and is admittedly a large dose of quinidine. However, it does not differ greatly from the single oral dose of $1.2 \mathrm{Gm}$. given by Starr, Gamble, Margolies, Donal, Joseph, and Eagle (6) or the $0.8 \mathrm{Gm}$. single oral dose administered by Ferrer, Harvey, Werkö, Dresdale, Cournand, and Richards ( 7 ) in their study of patients. Undoubtedly, a higher concentration reached the cardiovascular system following intravenous administration as used in the present study than in the clinical experiments utilizing the oral route of administration. Gold and Modell (15) used increasing doses from 2 to $40 \mathrm{mg}$. per $\mathrm{kg}$. intravenously in their study on dogs, representing a span on both sides of the dosage employed in this study.

Quinidine uniformly produces in dogs a tachycardia even at the $2 \mathrm{mg}$. per $\mathrm{kg}$. dose level (15). Since tachycardia is not observed in human subjects there is undoubtedly a species difference with respect to this action of the drug. Only further studies in man could clarify the question of different effects in various species. However, similar hemodynamic studies performed in dogs with hexamethonium have been completely applicable to human subjects, except for the species difference of tachycardia in the former (11).

\section{SUMMARY AND CONCLUSIONS}

1. The hemodynamic and cardiac effects of administration of quinidine intravenously to 16 dogs have been studied. For technical reasons, 13 of these proved satisfactory.

2. Tachycardia and hypotension followed immediately after administration of the drug, and although the blood pressure returned to the control range before the second determination of cardiac output, the cardiac rate remained elevated.

3. Cardiac output determination twenty-five minutes after quinidine was not significantly different from the control measurement.

4. Although right ventricular work and total pulmonary resistance decreased, left ventricular work and systemic arterial resistance remained unchanged.

5. Coronary blood flow and cardiac metabolic rate for oxygen increased considerably whereas coronary vascular resistance and myocardial efficiency decreased markedly.

6. The increase in myocardial oxygen consumption was associated with an increase in coronary 
blood flow and an increase in arterial-coronary sinus oxygen difference.

\section{REFERENCES}

1. Gold, H., Quinidine in Disorders of the Heart. New York, Paul B. Hoeber, Inc., 1950.

2. Webb, J. L., Saunders, P. R., and Nakamura, K., The metabolism of the heart in relation to drug action. VI. Metabolic actions of quinidine on rat heart muscle. J. Pharmacol. \& Exper. Therap., 1951, 101, 287.

3. Uyeki, E. M., Geiling, E. M. K., and Dubois, K. P., Studies on the effects of quinidine on intermediary carbohydrate metabolism. Arch. internat. de pharmcodyn. et de thérap., 1954, 97, 191.

4. Grisolia, S., The potentiating effect of digitoxin and quinidine on dinitrophenol uncoupling of oxidate phosphorylation. Biochem. \& Biophys. Acta, 1955, 18, 437.

5. Furman, R. H., and Howard, R. P., Metabolic effect of quinidine; evidence suggesting impairment of glucose utilization. Am. J. Med., 1955, 19, 140.

6. Starr, I., Gamble, C. J., Margolies, A., Donal, J. S., Jr., Joseph, N., and Eagle, E., A clinical study of the action of 10 commonly used drugs on cardiac output, work and size; on respiration, on metabolic rate and on the electrocardiogram. J. Clin. Invest., 1937, 16, 799.

7. Ferrer, M. I., Harvey, R. M., Werkö, L., Dresdale, D. T., Cournand, A., and Richards, D. W., Jr., Some effects of quinidine sulfate on the heart and circulation in man. Am. Heart J., 1948, 36, 816.
8. Kory, R. C., and Meneely, G. R., Cardiac output in auricular fibrillation with observations on the effects of conversion to normal sinus rhythm. J. Clin. Invest., 1951, 30, 653.

9. Allen, C. R., Stutzman, J. W., Slocum, H. C., and Orth, O. S., Protection from cyclopropane-epinephrine tachycardia by various drugs. Anesthesiology, 1941, 2, 503.

10. Wégria, R., and Boyle, M. N., Correlation between the effect of quinidine sulfate on the heart and its concentration in the blood plasma. Am. J. Med., 1948, 4, 373.

11. Crumpton, C. W., Rowe, G. G., O'Brien, G., and Murphy, Q. R., Jr., The effect of hexamethonium bromide upon coronary flow, cardiac work and cardiac efficiency in normotensive and renal hypertensive dogs. Circ. Research, 1954, 2, 79.

12. Shipley, R. E., and Gregg, D. E., The cardiac response to stimulation of the stellate ganglia and cardiac nerves. Am. J. Physiol., 1945, 143, 396.

13. Rowe, G. G., Huston, J. H., Maxwell, G. M., Weinstein, A. B., Tuchman, H., and Crumpton, C. W., The effects of 1-hydrazinophthalazine upon coronary hemodynamics and myocardial oxygen metabolism in essential hypertension. J. Clin. Invest., 1955, 34, 696.

14. Laurent, D., Bolene-Williams, C., Williams, F. L., and Katz, L. N., Effects of heart rate on coronary flow and cardiac oxygen consumption. Am. J. Physiol., 1956, 185, 355.

15. Gold, H., and Modell, W., The action of quinidine on the heart in the normal unanesthetized dog. J. Pharmacol. \& Exper. Therap., 1932, 46, 357. 